CERN-EP/98-130

August 7, 1998

\title{
Scintillating properties of frozen new liquid scintillators ${ }^{\star}$
}

\author{
G.I. Britvich ${ }^{1}$, F. Galeazzi ${ }^{2}$, S.V. Golovkin ${ }^{1}$, G. Martellotti ${ }^{2}$, \\ A.M. Medvedkov ${ }^{1}$, G. Penso ${ }^{2}$, A.S. Solovjev ${ }^{3}$, and V.G. Vasil'chenko ${ }^{1}$
}

\begin{abstract}
The light emission from scintillators which are liquid at room temperature was studied in the interval between $+20{ }^{\circ} \mathrm{C}$ and $-120{ }^{\circ} \mathrm{C}$, where the phase transition from liquid to solid takes place. The light yield measured at $-120^{\circ} \mathrm{C}$ is about twice as much as that observed at $+20^{\circ} \mathrm{C}$. By cooling the scintillator from $+20^{\circ} \mathrm{C}$ to $-120^{\circ} \mathrm{C}$ and then heating it from $-120^{\circ} \mathrm{C}$ to $+20^{\circ} \mathrm{C}$, the light yield varies in steps at well defined temperatures, which are different for the cooling and heating processes. These hysteresis phenomena appear to be related to the solvent rather than to the dopant. The decay time of scintillation light was measured at $+20{ }^{\circ} \mathrm{C}$ and $-120{ }^{\circ} \mathrm{C}$. Whilst at room temperature most of the light is emitted with a decay time of $6-8 \mathrm{~ns}$, at $-120{ }^{\circ} \mathrm{C}$ a slower component, with a decay time of 25-35 ns, becomes important.
\end{abstract}

PACS: 29.40.Mc; 29.40.Gx; 29.40.Vj

Keywords:Liquid scintillators, Scintillation detectors; Tracking and position-sensitive detectors; Calorimeters.

(Submitted to Nuclear Instruments 8 Methods A)

\footnotetext{
* This work is part of the CERN Research and Development programme RD46.

${ }^{1}$ IHEP, Protvino, Russian Federation.

${ }^{2}$ Università di Roma "La Sapienza" and INFN, Roma, Italy.

3 JINR, Dubna, Russian Federation.
} 


\section{Introduction}

In recent years, new liquid scintillators (LSs), emitting green light, have been developed [1-6]. At room temperature and in air these scintillators have a light yield which can reach $\sim 50 \%$ of that of an anthracene crystal. This light yield can be increased to $\sim 63 \%$ of that of an anthracene crystal if the air dissolved in the LSs is eliminated by a degassing procedure [7-9]. The relatively short decay time $(6-8 \mathrm{~ns})[3,5,6]$ and the high radiation hardness ( $>100 \mathrm{Mrad}$ ) [10] of these scintillators make them suitable for many applications in high-energy physics, such as high-resolution tracking with glass capillaries filled with LS, or electromagnetic and hadronic calorimetry.

In the present paper we present a study of the scintillation light yield of these LSs and of their solvents, in the temperature interval between $+20{ }^{\circ} \mathrm{C}$ and $-120{ }^{\circ} \mathrm{C}$, where the phase transition from liquid to solid takes place.

\section{Experimental method}

In order to measure the light yield of various scintillators at temperatures above and below their freezing point, we used a set-up already described [7], which allows the temperature of the sample tested to be varied from $-120{ }^{\circ} \mathrm{C}$ to $+20{ }^{\circ} \mathrm{C}$. The scintillators, placed on the photocathode of a FEU-84-3 photomultiplier, were irradiated with a ${ }^{90} \mathrm{Sr}$ $\beta$-source and the output current of the photomultiplier was measured with a precision of $\pm 5 \%$. The emission spectrum of the scintillators and the spectral sensitivity of the photocathode were measured and taken into account in order to deduce the light yield from the measured photomultiplier current. The overall error on the light yields is estimated to be $\pm 10 \%$. The system was calibrated by measuring the light yield of an anthracene crystal. Figure 1 shows the spectral sensitivity of the photocathode and the emission spectra of anthracene and of a typical green-emitting scintillator we are considering, at $-120{ }^{\circ} \mathrm{C}$ and $+20{ }^{\circ} \mathrm{C}$.

With this set-up we tested twelve scintillators based on 1-methylnaphthalene (1MN), 1-isopropylnaphthalene (IPN) and 1-phenylnaphthalene (1PN) doped with R6 ${ }^{1}$, R45, R39 and 3M-15. The scintillator samples were first cooled from $+20{ }^{\circ} \mathrm{C}$ to $-120{ }^{\circ} \mathrm{C}$, and then heated from $-120{ }^{\circ} \mathrm{C}$ to $+20{ }^{\circ} \mathrm{C}$. The highest light yield for frozen scintillators and the best reproducibility of the measurements is obtained when the temperature is varied very slowly: the temperature of the samples was changed at a rate of $d T / d t \leq$ $1^{\circ} \mathrm{C} /$ minute. The measurements were performed both in air at normal pressure, and in vacuum, after a suitable degassing time [7].

When frozen, most of the scintillators based on IPN and 1PN were transparent, while those based on $1 \mathrm{MN}$ were semitransparent. Therefore, in order to avoid loss of light due to self-absorption, a sample thickness of $1 \mathrm{~mm}$ was choosen. The light yields measured at $T=+20^{\circ} \mathrm{C}$ were normalized to the values obtained [7] at the same temperature with a sample thickness of $1 \mathrm{~cm}$.

\footnotetext{
${ }^{1} \mathrm{R} 6, \mathrm{R} 45, \mathrm{R} 39$ and 3M-15 are trade marks of the Geosphaera Research Centre, Vavilova 70/2, Moscow, 117261, Russian Federation.
} 


\section{Results}

\subsection{Influence of low temperature on scintillation light}

Following the experimental method described above, the light yield of 12 scintillators based on 1MN, IPN and 1PN solvents, doped with R6, R45, R39 or 3M-15 with a concentration of $\mathrm{C}=3 \mathrm{~g} / 1$, was measured at $+20{ }^{\circ} \mathrm{C}$ and $-120{ }^{\circ} \mathrm{C}$. For all of the scintillators the maximum light yield was attained at $-120^{\circ} \mathrm{C}$. In Table 1 we report the results of these measurements for scintillators kept in air at normal pressure or degassed in vacuum. As already observed with liquid scintillators [7], the degassing procedure also increases the light yield for frozen scintillators. Moreover, the light yield at $-120{ }^{\circ} \mathrm{C}$ is higher by a factor of $\approx 2$ with respect to that measured at $+20^{\circ} \mathrm{C}$. This increase is probably due to the reduction of thermal quenching at low temperature.

The scintillation light of pure solvents was also measured ${ }^{2}$ at $+20^{\circ} \mathrm{C}$ and $-120{ }^{\circ} \mathrm{C}$ and is shown in Table 1 . As with scintillators, the light yield of pure solvents increases at low temperature and after degassing. In particular, for pure $1 \mathrm{MN}$ at $T=-120{ }^{\circ} \mathrm{C}$ a light yield of $\sim 96 \%$ of that of anthracene is attained.

For the $1 \mathrm{MN}+\mathrm{R} 6$ scintillator, the light yield as a function of the dopant concentration was also measured. The results are shown in Fig. 2. For scintillators in air, at $+20{ }^{\circ} \mathrm{C}$ and $-120{ }^{\circ} \mathrm{C}$, a concentration of between 1.5 and $3 \mathrm{~g} / 1$, allows the maximum light yield with the minimum dopant concentration (and therefore with the minimum selfabsorption of the scintillation light) to be reached, whilst at $-120^{\circ} \mathrm{C}$ and for $1 \mathrm{MN}+\mathrm{R} 6$ degassed in vacuum, a dopant concentration between 1 and $2 \mathrm{~g} / 1$ gives the best results.

\subsection{Thermal hysteresis of scintillation light}

For four different scintillators $(1 \mathrm{MN}+\mathrm{R} 6,1 \mathrm{MN}+\mathrm{R} 45, \mathrm{IPN}+\mathrm{R} 6$ and $1 \mathrm{PN}+\mathrm{R} 6)$ the scintillation light during the cooling process from $+20{ }^{\circ} \mathrm{C}$ to $-120{ }^{\circ} \mathrm{C}$, and the subsequent heating from $-120^{\circ} \mathrm{C}$ to $+20^{\circ} \mathrm{C}$ was measured. The same measurements were also performed on the scintillation light of the pure solvents (1MN, IPN and 1PN). In Figs. 3, 4 and 5 the results of these measurements, which were performed in air at normal pressure and in vacuum after a suitable degassing time [7] are shown. During cooling of the sample from $+20{ }^{\circ} \mathrm{C}$ to $-120^{\circ} \mathrm{C}$, it was found, unexpectedly, that the light increases in steps which occur around well defined temperatures, whilst during subsequent heating, similars steps are observed, but at a systematically higher temperature. This phenomenum gives rise to the hysteresis loops observed in Figs. 3, 4 and 5. For LS based on IPN and $1 \mathrm{PN}$ (Figs. 4 and 5) only one loop is observed, whilst for those based on 1MN (Fig. 3) two distinct loops are present. By comparing these curves, we observe that those relative to a given LS and to the corresponding pure solvent have a very similar behaviour. This suggests that this phenomenum is due to a property of the solvent rather than that of the dopant.

In order to investigate this phenomenum, the light emission at $-18^{\circ} \mathrm{C}$ for $1 \mathrm{MN}+\mathrm{R} 6$ in air (the $1 \mathrm{MN}$ has a freezing temperature of $-28^{\circ} \mathrm{C}$ ) was measured, keeping this temperature constant for 40 minutes during the cooling process. The light yield measured during this period remains constant and equal to $\sim 47 \%$ of that of anthracene. Subse-

\footnotetext{
${ }^{2}$ The emission spectra of pure solvents, which peak in the blue region, have not been measured with the same precision as that of LSs. This results in a further error of $\pm 10 \%$ on the light yield of pure solvents, caused by the correction for the spectral sensitivity of the photocathode.
} 
Table 1: Light yield of the scintillators and of their pure solvents, at $T=20{ }^{\circ} \mathrm{C}$ and $T=-120{ }^{\circ} \mathrm{C} . L_{a}$ and $L_{v}$ are, respectively, their light yield in air (not degassed scintillators and solvents) and in vacuum (degassed scintillators and solvents) expressed in percentage of that of anthracene.

\begin{tabular}{lccccc}
\hline & \multicolumn{2}{c}{$T=+20^{\circ} \mathrm{C}$} & & \multicolumn{2}{c}{$T=-120^{\circ} \mathrm{C}$} \\
\cline { 2 - 3 } \cline { 5 - 6 } Scintillator & $L_{a}(\%)$ & $L_{v}(\%)$ & & $L_{a}(\%)$ & $L_{v}(\%)$ \\
\hline 1MN + R6 & 46.8 & 59.2 & & 96.0 & 109. \\
1MN + R45 & 47.3 & 58.6 & & 126. & 144. \\
1MN + R39 & 47.9 & 63.2 & & 80.8 & 120. \\
1MN + 3M-15 & 44.2 & 54.9 & & 116. & 123. \\
\hline IPN + R6 & 46.7 & 61.8 & & 101. & 109. \\
IPN + R45 & 44.6 & 56.6 & & 85.6 & 94.6 \\
IPN + R39 & 46.4 & 59.5 & & 73.8 & 92.4 \\
IPN + 3M-15 & 49.5 & 60.0 & & 94.6 & 106. \\
\hline 1PN + R6 & 34.8 & 37.4 & & 88.9 & 92.2 \\
1PN + R45 & 26.4 & 29.0 & & 68.1 & 69.3 \\
1PN + R39 & 31.9 & 35.3 & & 64.1 & 66.9 \\
1PN + 3M-15 & 31.0 & 34.7 & & 60.9 & 65.7 \\
\hline Solvent & & & & \\
\hline 1MN & 3.65 & 7.18 & 50.8 & 96.1 \\
IPN & 5.69 & 14.2 & 30.9 & 52.6 \\
1PN & 9.35 & 11.3 & 34.4 & 38.0 \\
\hline
\end{tabular}

quently, during the heating process, the temperature was again kept constant at $-18{ }^{\circ} \mathrm{C}$ during 40 minutes, and a stable light emission of $\sim 74 \%$ of that of anthracene was observed. These results were reproducible, thus giving confidence in our experimental method. During the two periods of observation at $-18{ }^{\circ} \mathrm{C}$, the $1 \mathrm{MN}+\mathrm{R} 6$ scintillator appears to be liquid during the cooling process, and solid during the heating phase. This observation suggests that the two steps around $-12{ }^{\circ} \mathrm{C}$ and $-32{ }^{\circ} \mathrm{C}$ correspond to the melting and freezing points of the scintillator, respectively, and that between these two temperatures the scintillator is in a supercooled (or superheated) stable state. These states are often encountered [11] in phase transitions of liquid crystals, and therefore the phenomena observed could be related to the presence of mesophases, which have already been observed [11] in many molecules based, like the $1 \mathrm{MN}$, on a double benzene ring. For IPN- and 1PN-based scintillators the single hysteresis loop (Figs. 4 and 5) occurs in the solid phase, the freezing temperature of these two solvents being, respectively, $-26{ }^{\circ} \mathrm{C}$ and $-7{ }^{\circ} \mathrm{C}$. A more detailed study, which is beyond the aim of this paper, would be necessary to investigate these phenomena. 
Table 2: Results of a fit to the decay time distribution of the scintillators. Data at $+20^{\circ} \mathrm{C}$ $\left(-120{ }^{\circ} \mathrm{C}\right)$ were fitted to the sum of two (three) exponentials with time constants $\tau_{i}$ and relative intensities $A_{i}$. The estimated relative errors are $\pm 6 \%$ on $\tau_{i}$ and $\pm 8 \%$ on $A_{i}$ with the exception of the weakest components $\left(A_{2}\right.$ at $+20^{\circ} \mathrm{C}$ and $A_{3}$ at $\left.-120^{\circ} \mathrm{C}\right)$ which are affected with a relative error of $\pm 50 \%$.

vspace -3. truemm

\begin{tabular}{|c|c|c|c|c|c|c|c|c|c|c|}
\hline \multirow[b]{2}{*}{ Scintillator } & \multicolumn{4}{|c|}{$T=+20^{\circ} \mathrm{C}$} & \multicolumn{6}{|c|}{$T=-120^{\circ} \mathrm{C}$} \\
\hline & $\begin{array}{c}\tau_{1} \\
(\mathrm{~ns})\end{array}$ & $\begin{array}{c}A_{1} \\
(\%)\end{array}$ & $\begin{array}{c}\tau_{2} \\
(\mathrm{~ns})\end{array}$ & $\begin{array}{c}A_{2} \\
(\%)\end{array}$ & $\begin{array}{c}\tau_{1} \\
(\mathrm{~ns})\end{array}$ & $\begin{array}{c}A_{1} \\
(\%)\end{array}$ & $\begin{array}{c}\tau_{2} \\
(\mathrm{~ns})\end{array}$ & $\begin{array}{c}A_{2} \\
(\%)\end{array}$ & $\begin{array}{c}\tau_{3} \\
(\mu \mathrm{s})\end{array}$ & $\begin{array}{l}A_{3} \\
(\%)\end{array}$ \\
\hline $1 \mathrm{MN}+\mathrm{R} 6$ & 7.6 & 96 & 40 & 4 & 10.3 & 54 & 35 & 44 & 1.0 & 2 \\
\hline $1 \mathrm{MN}+\mathrm{R} 45$ & 6.8 & 96 & 35 & 4 & 11.3 & 58 & 32 & 39 & 0.28 & 3 \\
\hline $1 \mathrm{MN}+\mathrm{R} 39$ & 6.8 & 96 & 35 & 4 & 7.7 & 71 & 29 & 26 & 0.33 & 3 \\
\hline $1 \mathrm{MN}+3 \mathrm{M}-15$ & 6.5 & 97 & 25 & 3 & 7.5 & 75 & 25 & 23 & 1.0 & 2 \\
\hline $\mathrm{IPN}+\mathrm{R} 6$ & 6.3 & 96 & 40 & 4 & 11.4 & 56 & 35 & 41 & 1.0 & 3 \\
\hline $\mathrm{IPN}+\mathrm{R} 45$ & 6.2 & 96 & 35 & 4 & 11.2 & 56 & 35 & 41 & 0.48 & 3 \\
\hline IPN+R39 & 6.2 & 96 & 35 & 4 & 6.8 & 77 & 31 & 20 & 0.56 & 3 \\
\hline $\mathrm{IPN}+3 \mathrm{M}-15$ & 6.2 & 97 & 30 & 3 & 8.4 & 76 & 29 & 22 & 0.99 & 2 \\
\hline
\end{tabular}

\subsection{Light emission time of liquid and frozen scintillators}

The decay time of light pulses emitted by the $1 \mathrm{MN}$ - and IPN-based scintillators was measured at $+20{ }^{\circ} \mathrm{C}$ and $-120{ }^{\circ} \mathrm{C}$, using the single-photoelectron delayed-coincidence counting method [12]. The measurements were performed in the $0-1 \mu$ s range, with a time resolution of $\sim 0.5 \mathrm{~ns}$. The scintillators were kept in air at normal pressure and were excited with a ${ }^{90} \mathrm{Sr} \beta$-source. As an example, Fig. 6 shows the first part $(t \leq 230 \mathrm{~ns})$ of the measurements performed on the $1 \mathrm{MN}+\mathrm{R} 6$ scintillator at $+20{ }^{\circ} \mathrm{C}$ and $-120^{\circ} \mathrm{C}$. As expected, the decrease in thermal quenching at low temperature results in the appearance of slow decay components in the light emission. Similar curves, obtained for other $1 \mathrm{MN}$ - and IPN-based scintillators at $+20{ }^{\circ} \mathrm{C}\left(-120{ }^{\circ} \mathrm{C}\right)$, are fitted, after subtraction of the accidental rate, to two (three) exponentials. In Table 2 the time constant and relative intensity of the decay components obtained from these fits are given.

\section{Conclusions}

The light yield of scintillators based on $1 \mathrm{MN}$, IPN and 1PN doped with R6, R45, R39 and $3 \mathrm{M}-15$, was measured in the temperature interval between $+20^{\circ} \mathrm{C}$ and $-120^{\circ} \mathrm{C}$, where the phase transition from liquid to solid takes place. On average the degassing procedure applied to these liquid scintillators increases their light yield by $\sim 30 \%$. A further increase of a factor of $\sim 2$ is obtained by freezing them at $-120^{\circ} \mathrm{C}$. For the best scintillator $(1 \mathrm{MN}+\mathrm{R} 45)$ the degassing procedure and freezing to $-120^{\circ} \mathrm{C}$ increase the light yield by a factor of $\sim 3$. For this scintillator this corresponds to a light yield of $144 \%$ of that of anthracene, which is much higher than that of any plastic scintillator. 
In the temperature interval explored, the dependence of the light yield on the temperature shows one or two peculiar hysteresis loops which seem to be related to the nature of the solvent rather than that of the dopant.

The decay time of the scintillation light was also studied, and it was found that at $+20^{\circ} \mathrm{C}$ most of the light is emitted with a decay time of $6-8 \mathrm{~ns}$, whilst at $-120^{\circ} \mathrm{C}$ a slower component is present in the light emission, with a decay time in the range of $25-35$ ns.

\section{Acknowledgments}

The authors would like to thank K.V. Zimyn for his help during the measurements of the scintillating light yield.

\section{References}

[1] S.V.Golovkin et al., Nucl. Instr. and Meth. A305 (1991) 385.

[2] C. Cianfarani et al., Nucl. Instr. and Meth. A339 (1994) 449.

[3] A. Cardini et al., Nucl. Instr. and Meth. A346 (1994) 163.

[4] S. Buontempo, et al., Nucl. Instr. and Meth. A360 (1995) 7.

[5] A. Cardini et al., Nucl. Instr. and Meth. A361 (1995) 129.

[6] S.V.Golovkin et al., Preprint IHEP 96-13, 1996, Protvino.

[7] S. Buontempo et al., Nucl. Instr. and Meth. A (to be published); Preprint CERN-EP/98-129.

[8] P.Annis et al., Nucl. Phys. B (Proc. Suppl.) 61B (1998) 390.

[9] S.V.Golovkin et al., Preprint IHEP 97-12, 1997, Protvino.

[10] S.V.Golovkin et al., Nucl. Instr. and Meth. A362 (1995) 283.

[11] G. W. Gray, Molecular Structure and the Properties of Liquid Crystals (Academic Press, London, 1962).

[12] L.M.Bolinger and G.E.Thomos, Rev. Sci. Instr. 32 (1961) 1044. 


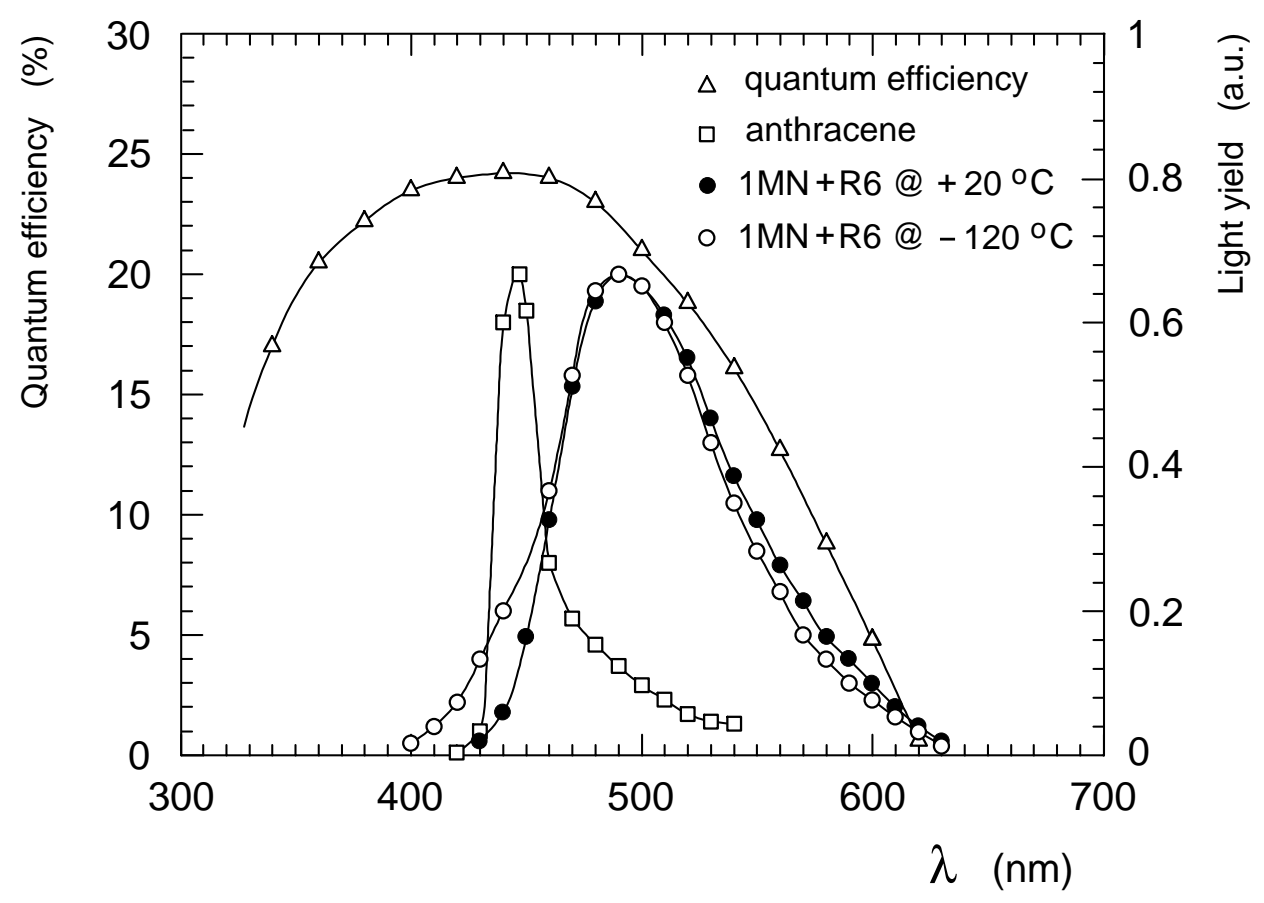

Figure 1: Quantum efficiency (left scale) of our photomultiplier as a function of the light wavelength, and emission spectra (right scale) of anthracene and of a typical green-emitting scintillator $(1 \mathrm{MN}+\mathrm{R} 6)$ at $+20{ }^{\circ} \mathrm{C}$ and $-120{ }^{\circ} \mathrm{C}$.

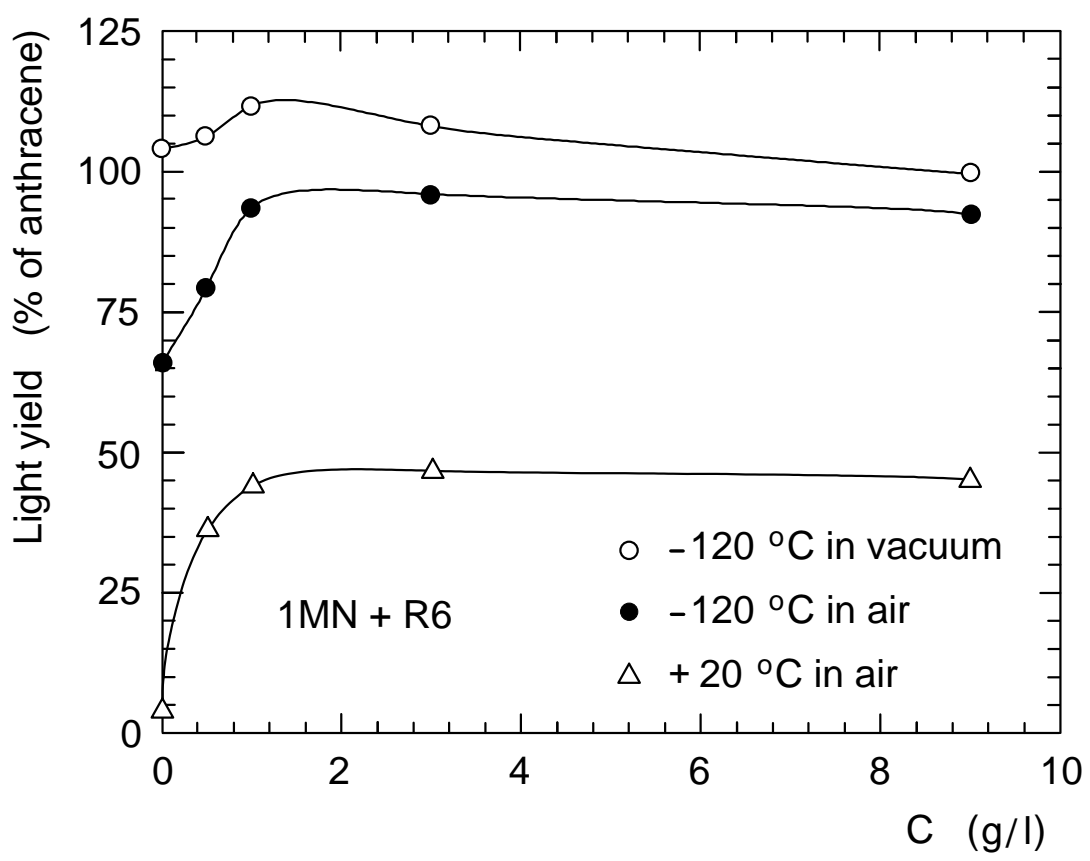

Figure 2: Light yield as a function of dopant concentration for $1 \mathrm{MN}+\mathrm{R} 6$ scintillator, in air at $-120^{\circ} \mathrm{C}$ and $+20{ }^{\circ} \mathrm{C}$, and in vacuum at $-120^{\circ} \mathrm{C}$. 


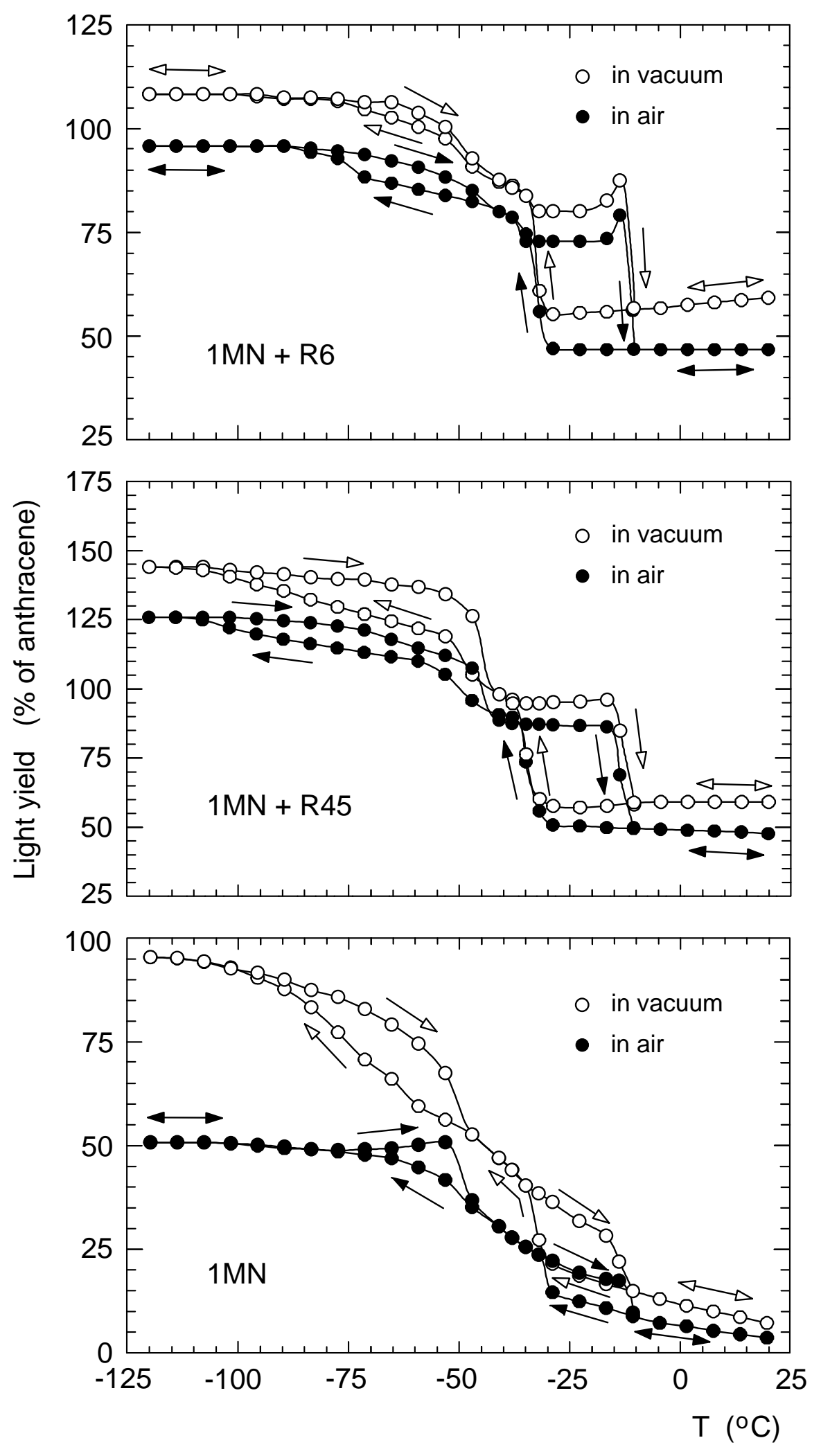

Figure 3: Light yield as a function of temperature of $1 \mathrm{MN}+\mathrm{R} 6$ and $1 \mathrm{MN}+\mathrm{R} 45$ scintillators and of pure $1 \mathrm{MN}$ solvent. The measurements were performed in air at normal pressure and in vacuum after a suitable degassing time. The arrows indicates the time sequence of the measurements during the cooling and heating processes. 


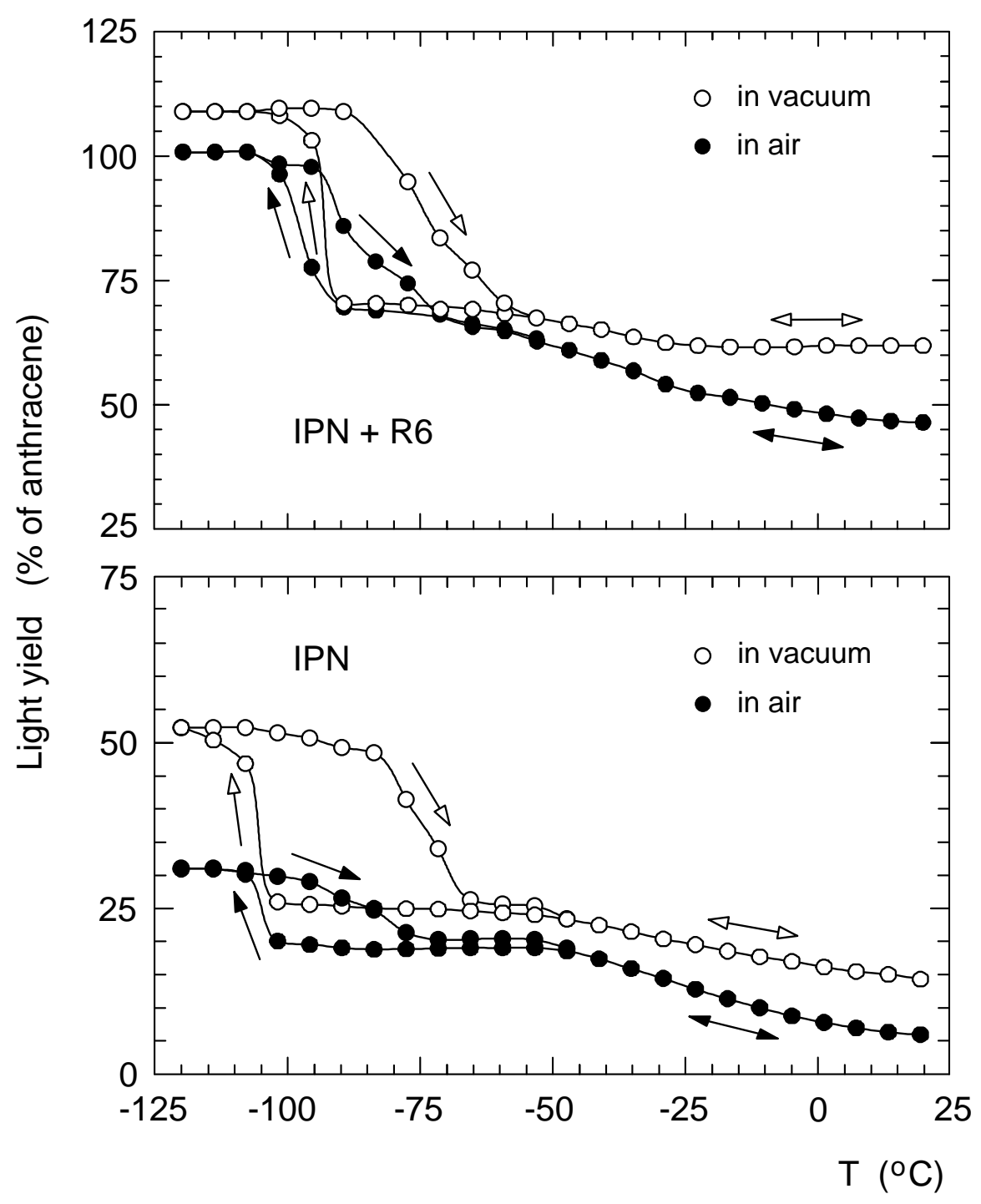

Figure 4: Light yield as a function of temperature of IPN+R6 scintillator and of pure IPN solvent. The measurements were performed in air at normal pressure and in vacuum after a suitable degassing time. The arrows indicates the time sequence of the measurements during the cooling and heating processes. 


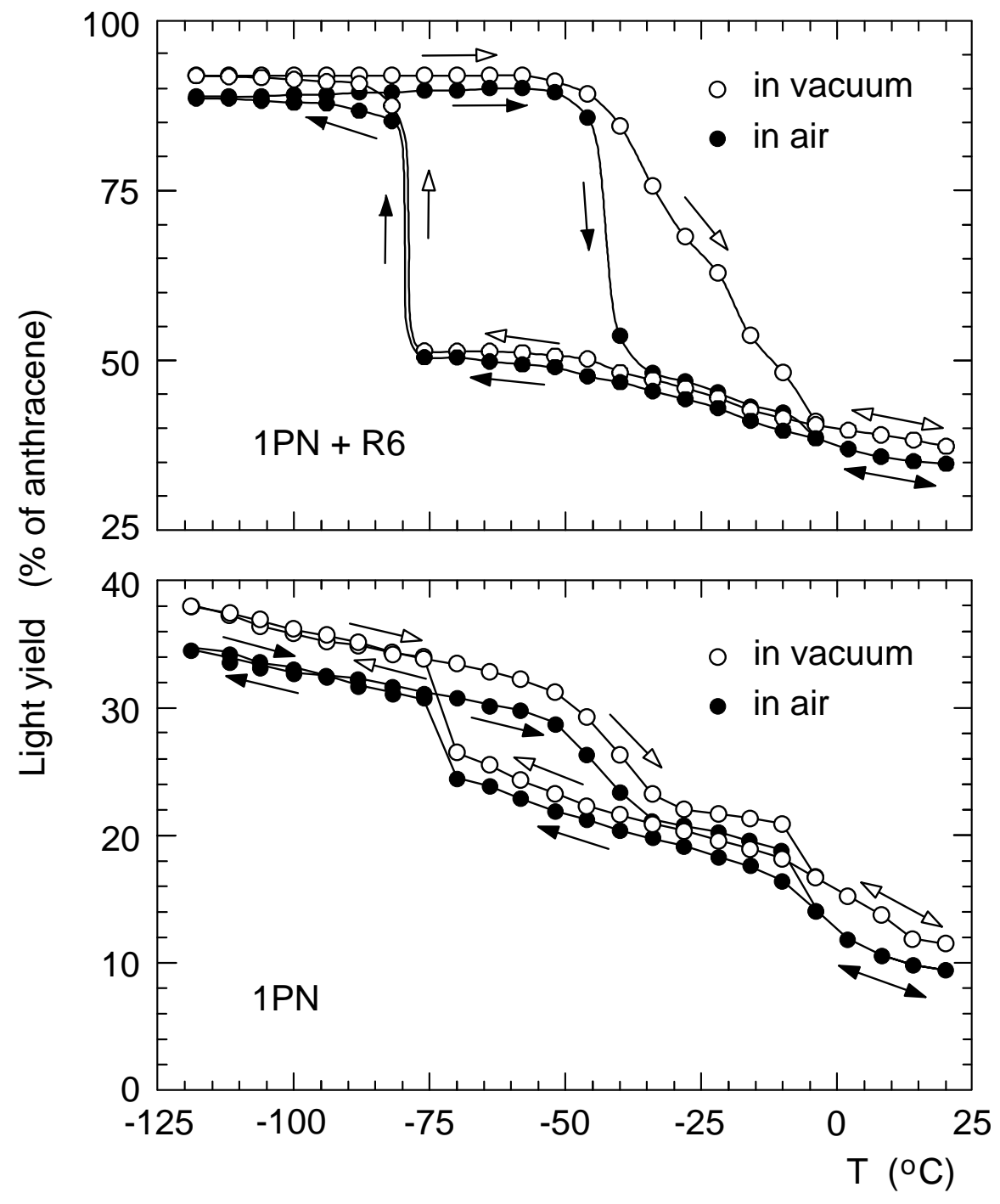

Figure 5: Light yield as a function of temperature of $1 \mathrm{PN}+\mathrm{R} 6$ scintillator and of pure $1 \mathrm{PN}$ solvent. The measurements were performed in air at normal pressure and in vacuum after a suitable degassing time. The arrows indicates the time sequence of the measurements during the cooling and heating processes. 


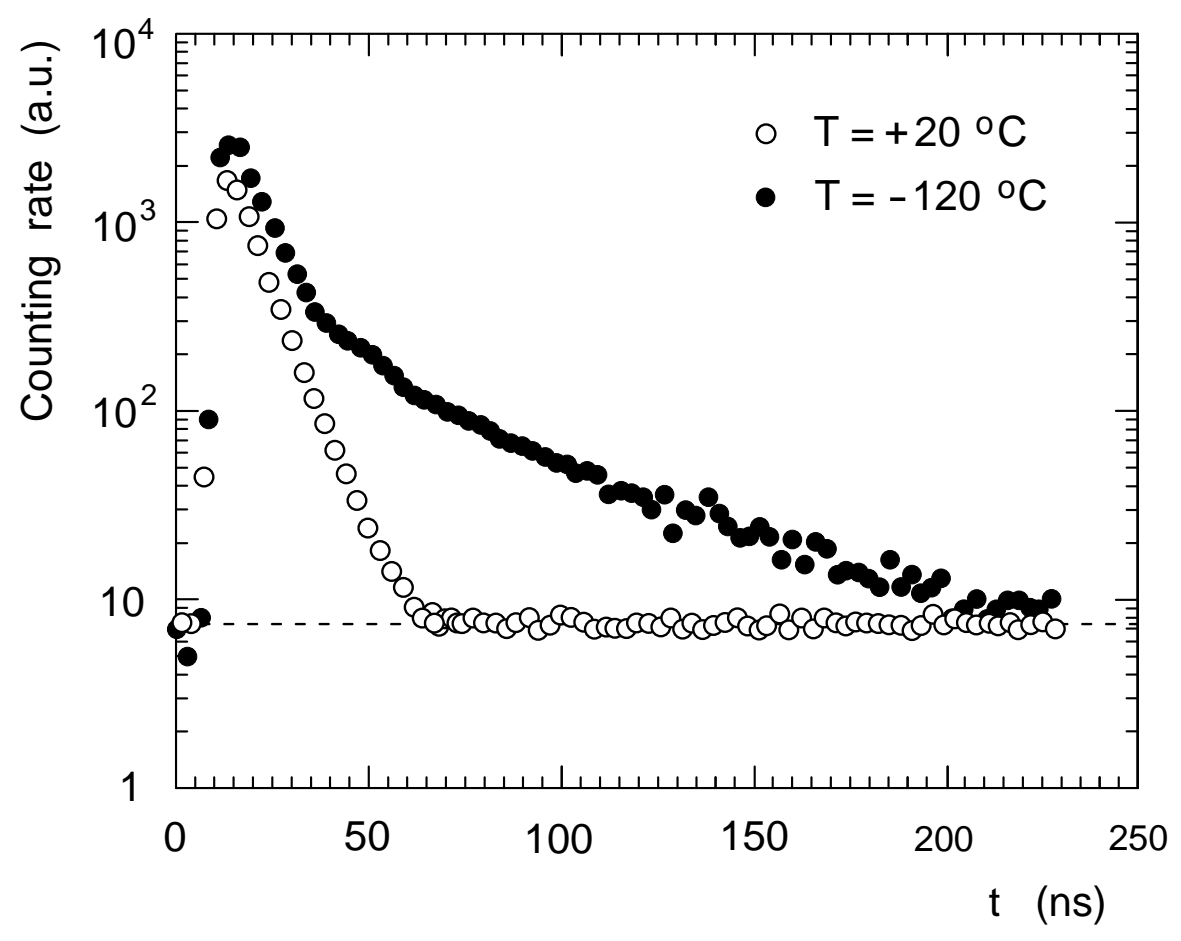

Figure 6: Emission time of $1 \mathrm{MN}+\mathrm{R} 6$ scintillator at $+20{ }^{\circ} \mathrm{C}$ and $-120{ }^{\circ} \mathrm{C}$. The curves are obtained with the single-photoelectron delayed-coincidence counting method. The dashed line indicates the average rate of accidentals. 